\title{
WATER VAPOR IN VENUS DETERMINED BY AIRBORNE OBSERVATIONS OF THE $8200 \AA$ BAND
}

\author{
THEODORE R. GULL* and C. R. O'DELL** \\ Yerkes Observatory, Williams Bay, Wis., U.S.A. \\ and \\ R. A. R. PARKER ‡ \\ Johnson Space Center, Houston, Tex., U.S.A.
}

\begin{abstract}
The region of the $8200 \AA$ Band of $\mathrm{H}_{2} \mathrm{O}$ was studied in spectra of Venus obtained with an echelle grating spectrograph operated at an altitude of $14.6 \mathrm{~km}$ in the NASA Learjet research aircraft. Taking advantage of low foreground absorption, observing at a time of velocity quadrature, differential spectroscopy with respect to lunar spectra, and spectrum averaging, we establish a value of $\mathrm{H}_{2} \mathrm{O}$ of $3 \pm 20 \mu$ for the total path over the entire disk. This value differs from earlier studies of the integrated disk but supports the low values recently derived from infrared bands and by very high spectral resolution groundbased studies.

These results establish that the average value over the entire disk is quite low but allows that locally larger values may exist as reported by Barker. A more complete description of this work appeared in Icarus 21 (1974), 213.
\end{abstract}

\section{DISCUSSION}

Barker: Comment; The McDonald data have high spatial resolution on the disk of Venus. Some positions show large amounts of $\mathrm{H}_{2} \mathrm{O}$ whereas others show non-detectable amounts similar to those of O'Dell, and Traub and Carleton, who looked basically at the integrated disk values. The average or integrated disk values must be lower than the largest amounts.

Baum: Comment; I hope that the spectroscopic observations of Venus reported at this symposium will be repeated during other time intervals. The features in ultraviolet images are found to change in strength considerably, particularly from one year to another. It would be helpful to know whether spectra reveal similar (perhaps correlated) variations.

* Now at the Kitt Peak National Observatory

** Now on leave at the George C. Marshall Space Flight Center

$\ddagger$ On leave from the University of Wisconsin 